\title{
A Framework for Measuring the Spatial Equity in the Distribution of Public Transportation Benefits
}

\author{
Seyed Amir Hosein Mortazavi and Meisam Akbarzadeh \\ Isfahan University of Technology, Iran
}

\begin{abstract}
This paper proposes that an equitable transit system requires that the geographical distribution of transit service benefits conform to the geographical distribution of the citizens with the greatest need for public transportation. This is the essence of vertical equity. This study calculated "connectivity power," which reflects public transit service quality in each traffic analysis zone (TAZ) in a city to indicate the amount of benefit that TAZ is receiving from the transit system. The number of carless citizens in each TAZ was also calculated as an index of need to the public transit services in that area. Conformity of need and supply was analyzed using Spearman's rank correlation and the Gini index. This framework indicates that in Isfahan, Iran, adding three bus rapid transit (BRT) lines and completing the existing metro line would not improve the Gini index but would improve the Spearman's rank correlation to an acceptable level.
\end{abstract}

Keywords: Equity, traffic analysis zone, Gini index, Spearman's Rank Correlation.

\section{Introduction}

Public transportation has certain merits, including high productivity of inputs (e.g., fuel and urban infrastructure capacity) and compliance with sustainable development. Therefore, promoting public transportation is one of the priorities of modern urban management. To evaluate transportation equity, it is important to measure the distribution of public transit service benefits and costs. This requires a rigorous theoretical and computational framework so that urban management is able to evaluate the current status as well as the consequences of future plans. This paper proposes a framework for evaluating the equity in the distribution of the public transportation benefit and applies it to the public transportation system of Isfahan, Iran. Various studies throughout the world have been carried out and reported in the literature, including Ricciardi et al. (2015), Griffin et al. (2015), and Iseki (2016). 
From the point of view of passengers, the benefits of public transportation include mobility (operational speed) and accessibility (access to stations, access the intended destination, waiting and transfer convenience). Various public transportation benefits as well as a variety of equity definitions and the difficulty of matching executive plans to definitions have led to a kind of obscurity in both theoretical and practical aspects of public transportation equity (El-Geneidy et al. 2013). To avoid this obscurity, a clear definition of equity and an exact realm of factors of interest for evaluation are discussed in this paper.

In terms of the availability of travel alternatives, citizens can be divided into two groups- "choice" and "captive" transit users. Choice users have at least two motorized alternative modes to accomplish their urban trips. Usually, this implies that choice users have a car at their disposal and also can select a transit or paratransit mode. On the other hand, captive users have only one motorized mode for their intra-urban trips, which can be due to the their lack of ownership or access to car and/or financial, health, or age situation or travel conditions.

Most captive users are lower-income (Welch 2013; Manaugh and El-Geneidy 2012). Consequently, a key function of a public transportation system is filling the utilization gap among different income classes. This function is carried out by providing access to destinations (especially to job opportunities) for captive users. The importance of the public transportation system is to the extent that, in some research, more suitable accessibility is considered a reason for gathering low-income households in neighborhoods near downtown (Kahn et al. 2008).

Spatial mismatch theory perceives the geographical distance between citizen residence and their available job opportunities as an urban issue. Transportation mismatch theory studies the mismatch among transportation infrastructure (including highways and public transportation facilities) with citizen job opportunity access demand (Ong and Miller 2005). Accordingly, covering urban expansion caused physical distance between origin and destination using public transportation is a progressive challenge of lowincome citizens.

Various approaches for quantification of the equity concept are proposed in the literature. Litman (2002) gives a thorough review of these definitions. Horizontal and vertical equities are two main approaches in this regard. Equal distribution of benefits among all social classes is known as horizontal equity. Vertical equity in public transportation requires distribution of benefits according to the need of each social class to those services (Murray and Davis 2001). In this definition, cost of service and the purchasing power of citizens are not taken into account.

Martins et al. (2012) considered the social meaning of a good as its equitable distribution criterion. For essential goods (e.g., bread, water), equity would be served by a uniform distribution. However, for luxury goods, due to their social meaning and usage by specific social groups, supply zone distribution should be determined by demand market norms. Social meaning of public transportation service is not identical for all citizens. Public transportation is considered an essential good for captive users 
but only an option for choice users. Therefore, to consider the citizen dependence factor, it is better to distribute public transportation services based on vertical equity.

Social equity in public transportation has been the focus of several research papers. As an example of recent endeavors, Currie (2010) studied the gap in transit supply based on social needs. He developed indexes for supply and demand and evaluated the conformity of the supply and need throughout various districts of Melbourne, Australia. The supply index included the number of stations within a zone, the frequency of service in each station, and the ratio of covered area of a zone to its total area. The demand index was a linear function of various characteristics of a zone, including the number of adults without a car, persons over age 60 , students, etc. The supply and need were plotted against each other, and regions with low conformity of supply and need were detected.

Based on supply-demand analysis using the Gini coefficient, Bertolaccini and Lownes (2013) investigated the effects of scale and boundary selection in assessing the equity of transit supply distribution. They calculated Gini coefficients for six urban transit systems within the United States within two boundaries (Metropolitan Statistical Area and Transit Service Area) at two scales (Census Tract and Block Group) and adopted two different demand measures (population and population plus employment). The results suggest that calculations with Gini coefficients on the basis of various boundary definitions can lead to significantly different comparative results, but the different scales and demand measures had insignificant impact on interregional comparisons.

Lemans (2016) adopted the Gini index, Theil index, and descriptive statistics to measure the equity of accessibility in an area of Utrecht, Netherlands. The descriptive statistics included the mean, variance, range, and coefficient of variation of the value of accessibility throughout the study area. Two situations (current as of 2015 and future as of 2020) were considered in the evaluation. A noticeable conclusion of the research was that the Gini index outperforms the Theil index and the descriptive statistics. The reason is that the Theil index used the average accessibility per resident in a zone, whereas the accessibility of each zone was determined by summing the contribution of stops located in it. The disadvantage of the descriptive statistics was the high sensitivity of the obtained scores to outliers in the study area.

\section{Methodology}

The methodology adopted in this paper is illustrated in Figure 1. In the first step, a clear definition of equity must be selected. As mentioned in the previous section, vertical equity was selected as the definition fitting the topic of public transportation benefits distribution. The definition of vertical equity has three keywords-benefit, need, and distribution. In the second step, measures were developed to pinpoint these keywords and quantify their values. 
FIGURE 1.

Flowchart of analysis

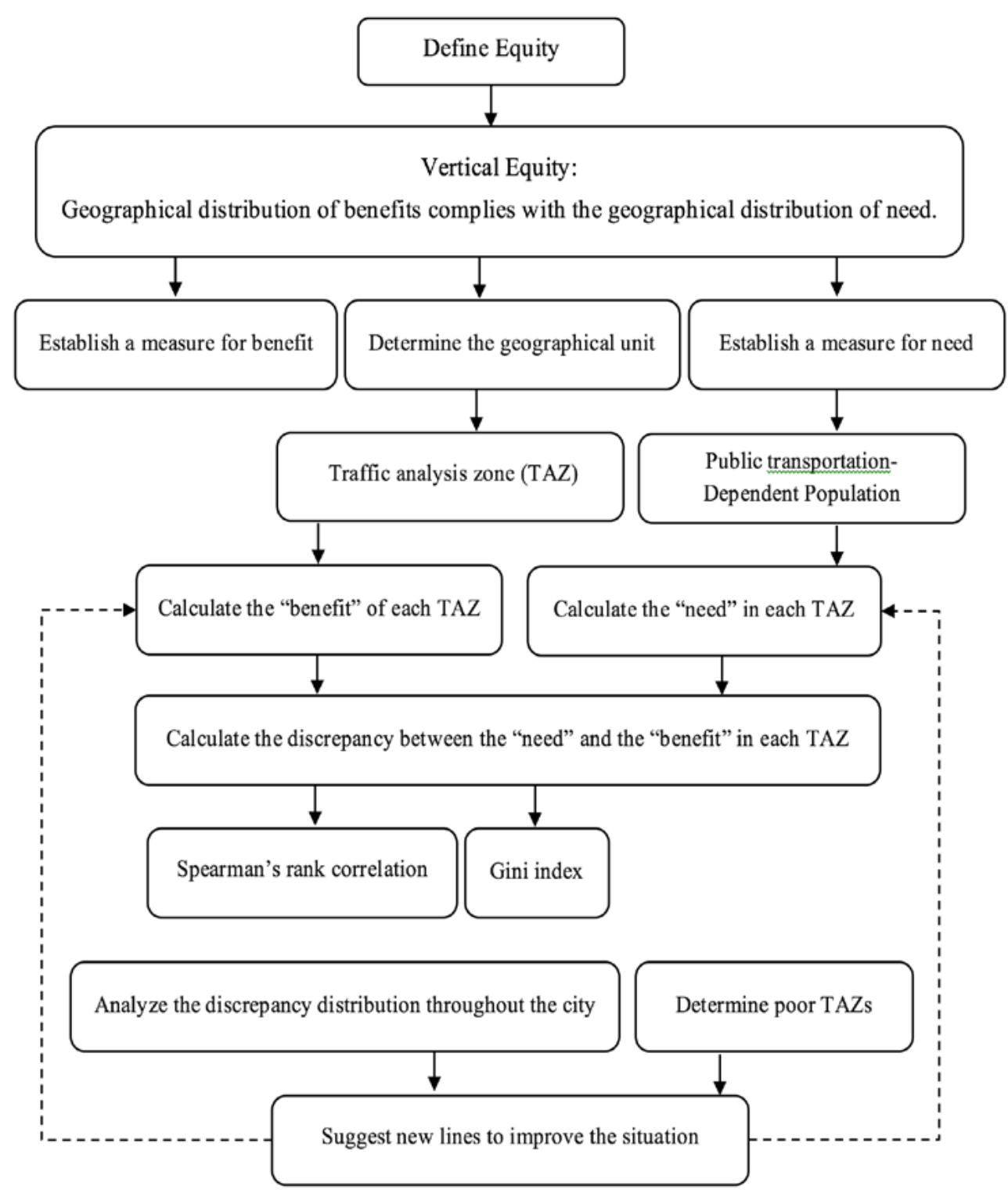

As the trip and socio-economic data are usually available for traffic analysis zones (TAZs), TAZs were selected as the geographical units for evaluating the distribution of benefit and need.

Benefit was formulated as "connectivity power," which is a function of accessibility and mobility similar to (but not the same as) the formulation of Welch et al. (2013) and Kaplan et al. (2014). In public transportation systems, stations bridge demand with supply. Connectivity power of a station (transit service quality index) shows how well it is connecting the demand to the whole network and the urban area. The connectivity power of station $n$ brought about by a line $\left(P_{l, n}\right)$ is the product of vehicle capacity $\left(C_{l}\right)$, frequency $\left(f_{l}\right)$, service hours $\left(H_{l}\right)$, speed $\left(V_{l}\right)$, and the number of stations $\left(D_{l}\right)$ of that line. The relation is presented in equation (1).

$$
P_{l, n}=C_{l} \cdot f_{l} \cdot H_{l} \cdot D_{l} \cdot V_{l}
$$


Total power of a station $\left(P_{n}\right)$ equals the summation of power of the lines passing through it.

$$
P_{n}=\sum_{l, n \in l} P_{l, n}
$$

To calculate the amount of benefit a public transportation system is providing to a TAZ, one only needs to add up the power of all the stations within that TAZ.

Need in each TAZ was estimated by the population of captives, i.e., citizens without car. In each TAZ $i$, number of transit-dependent residents or simply the index for need $\left(N_{i}\right)$ is equal the product of the population $\left(P_{i}\right)$ and the car ownership $\left(C_{i}\right)$. Therefore:

$$
N_{i}=P_{i} \times\left(1-C_{i}\right)
$$

Car ownership rate in each TAZ was obtained from the comprehensive survey recently conducted in Isfahan.

Once the need for public transportation service and provided benefits in each TAZ are determined, instruments are needed to evaluate the distribution of need and benefit throughout the urban area. The first step taken in this regard was to assess the conformity among the rank of TAZs according to need and benefit. This framework assumes that the distribution of transit services reflects local needs, so areas that have greater needs receive greater services. To assess conformity among the rank of TAZs in need and benefit lists, the list of TAZs was sorted according to need, and the rank of each TAZ was determined. Then, the list of TAZs was sorted according to benefit, and the rank of each TAZ was determined. Then, Spearman's correlation coefficient was calculated, as shown in equation (4).

$$
r_{s}=1-\frac{6 \times \sum_{i=1}^{m} d_{i}^{2}}{\left(m^{3}-m\right)}
$$

Where $d_{i}$ indicates the difference of ranking of a zone in the two directories and $m$ indicates the number of zones. $r_{s}$ follows Student's $t$ distribution with degrees of freedom equal to $m-2$ and, therefore, its statistical significance can be determined (Siegel 1956).

In addition to assessing the conformity of orders of need and benefit, overall distribution of benefits among zones was analyzed by calculating the Gini index. From an economic perspective, complete equality means a situation in which all process gains are equally distributed among community members (Welch 2013). A profile of this status is the first quadrant coordinate system.

The Gini coefficient indicates the distance of the current situation from the ideal situation, which means complete equality. In fact, the Gini index illustrates the surface between two diagrams of complete equality and the current situation. The mathematical definition of Gini index is as follows:

$$
G_{a}=1-\sum_{k=1}^{n}\left(X_{k}-X_{k-1}\right)\left(Y_{k}+Y_{k-1}\right)
$$

In complete equity, the value of this index is zero and in the worst condition is 1. 


\section{Case Study}

Isfahan has a population of 1.7 million and an area of approximately 500 square kilometers and is located in central Iran. Isfahan's bus system consists of 92 lines and 1,753 active stations, including one active bus rapid transit (BRT) line with 32 stations and one subway line (the first phase of Line 1) with 10 active stations. It is expected that within two years, three additional BRT lines will be added to the public transportation system of the city. Line 1 of the Isfahan BRT was launched in 2012; up until then, there was only regular bus line throughout the city. Figure 2 depicts the evolution of the Isfahan transit network since 2012 to 2018. The dark blue line shows the part of metro line currently in use, the green line shows the current BRT line, the light blue lines show three future BRT lines, and the red line shows the future extension of the metro line of Isfahan.

Data on TAZ boundaries, their population, and car ownership came from a comprehensive transportation study conducted by the Isfahan municipality. Data on public transportation services were obtained from the Isfahan Metropolitan Transit Organization.

FIGURE 2.

Evolution of Isfahan transit network

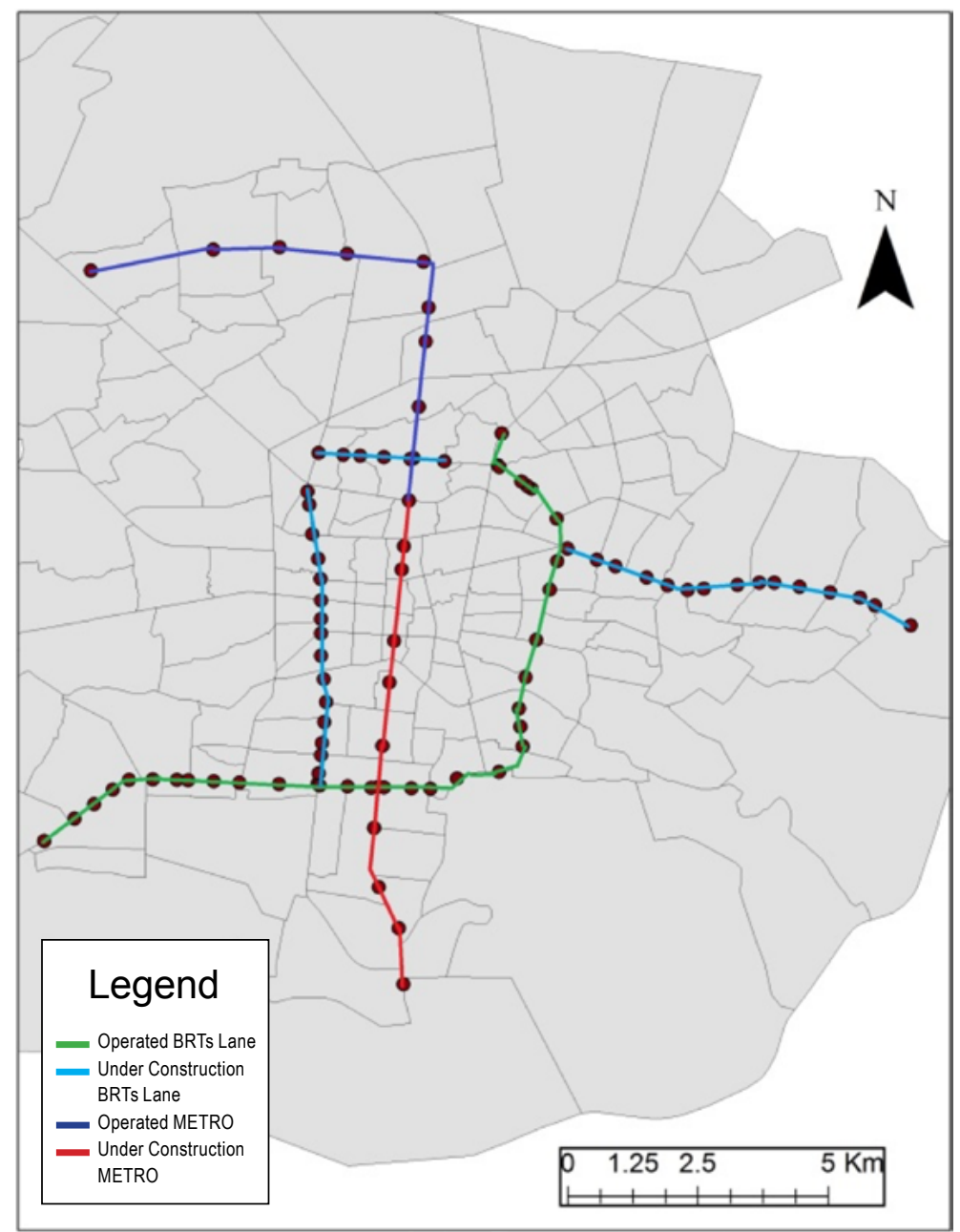


Based on the proposed framework, the condition in the base year (2012), the current condition (2016), and the future condition (2018) after completion of all BRT lines and the metro line were viewed and compared from the equity point of view. Data on supply side were collected from the Isfahan Metropolitan Bus Company.

Figures 3 through 5 illustrate the distribution of station power throughout the central part of Isfahan in three conditions.

FIGURE 3.

Distribution of station power in base condition

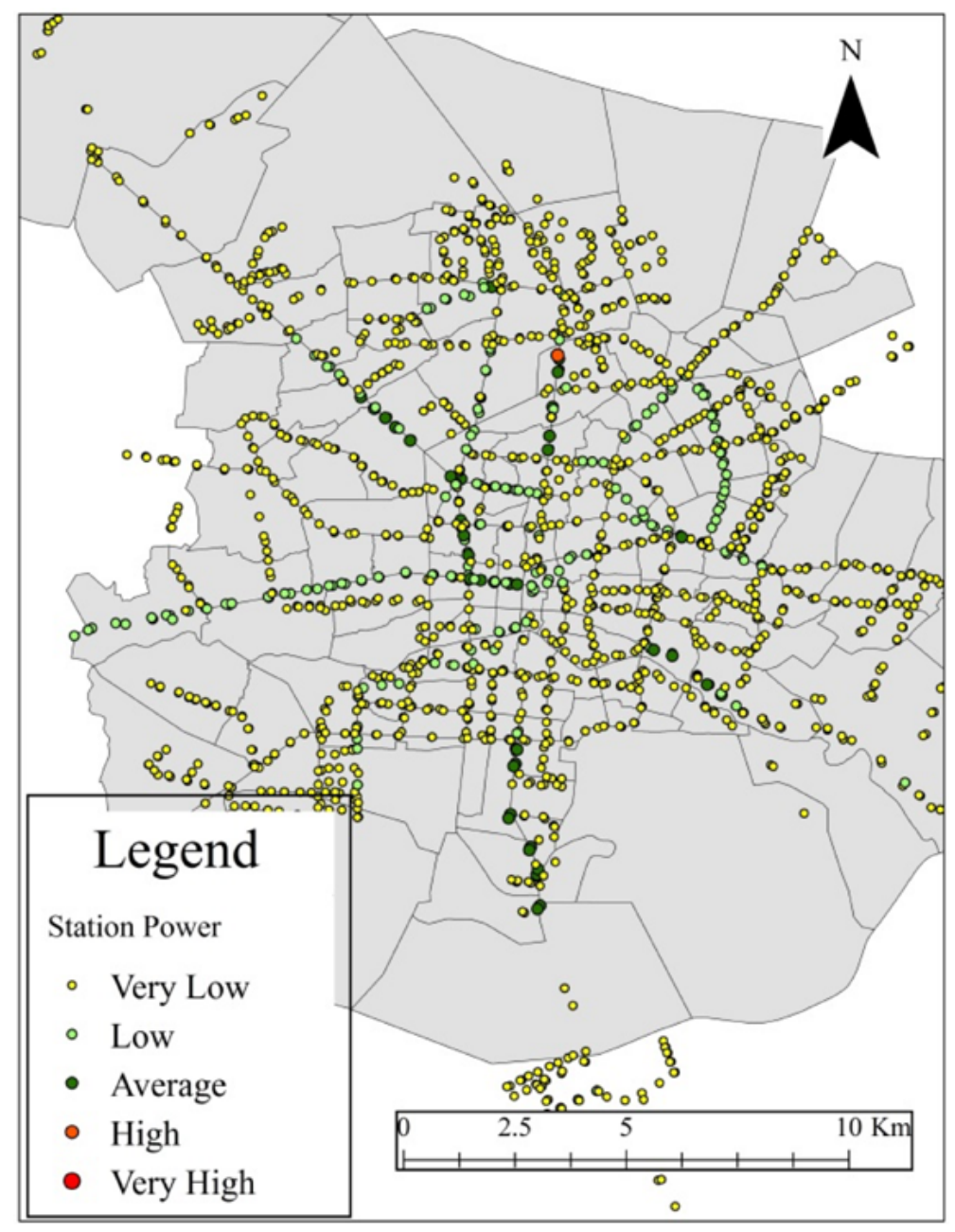


FIGURE 4.

Distribution of station power in current state

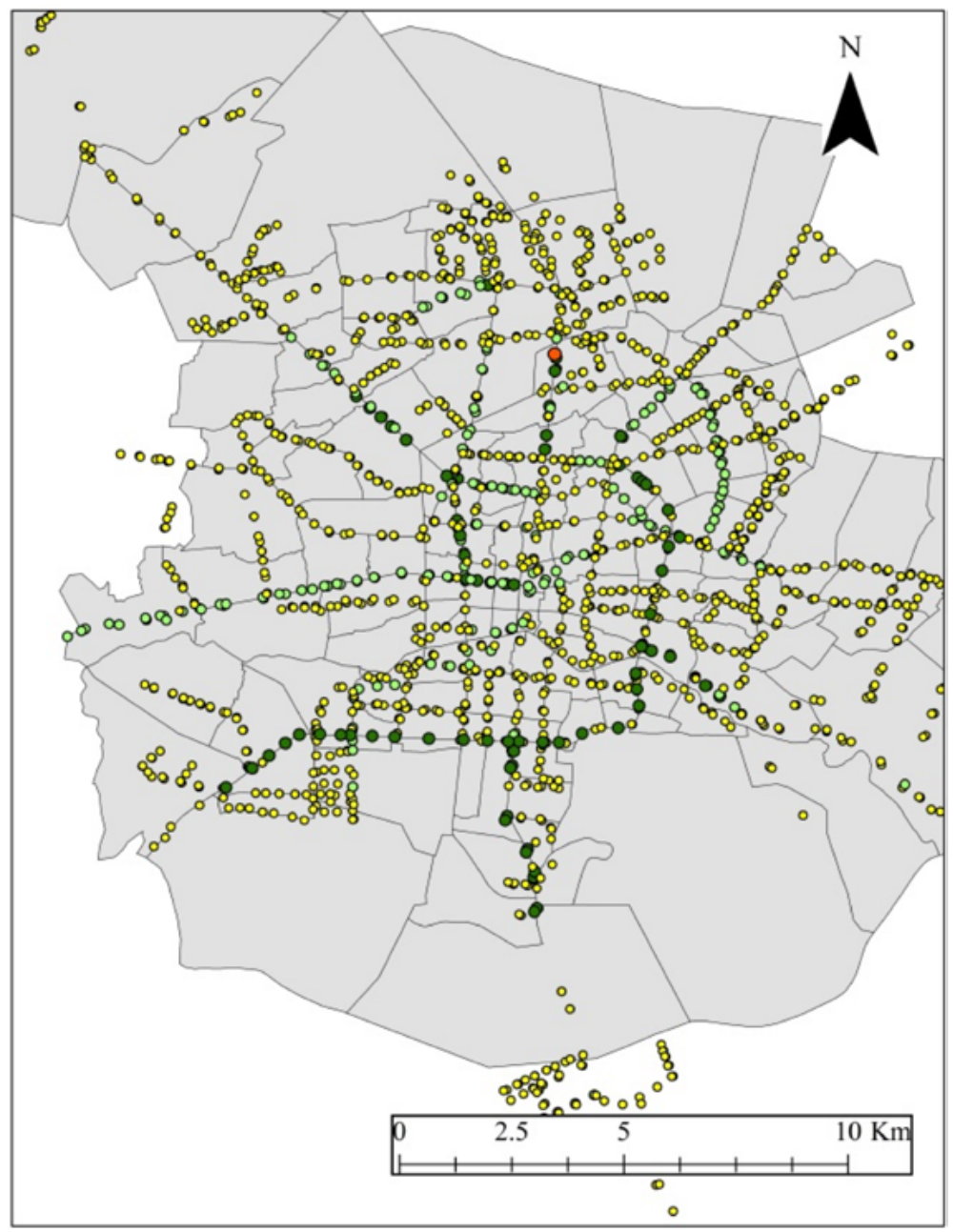


FIGURE 5.

Distribution of station power

in future state

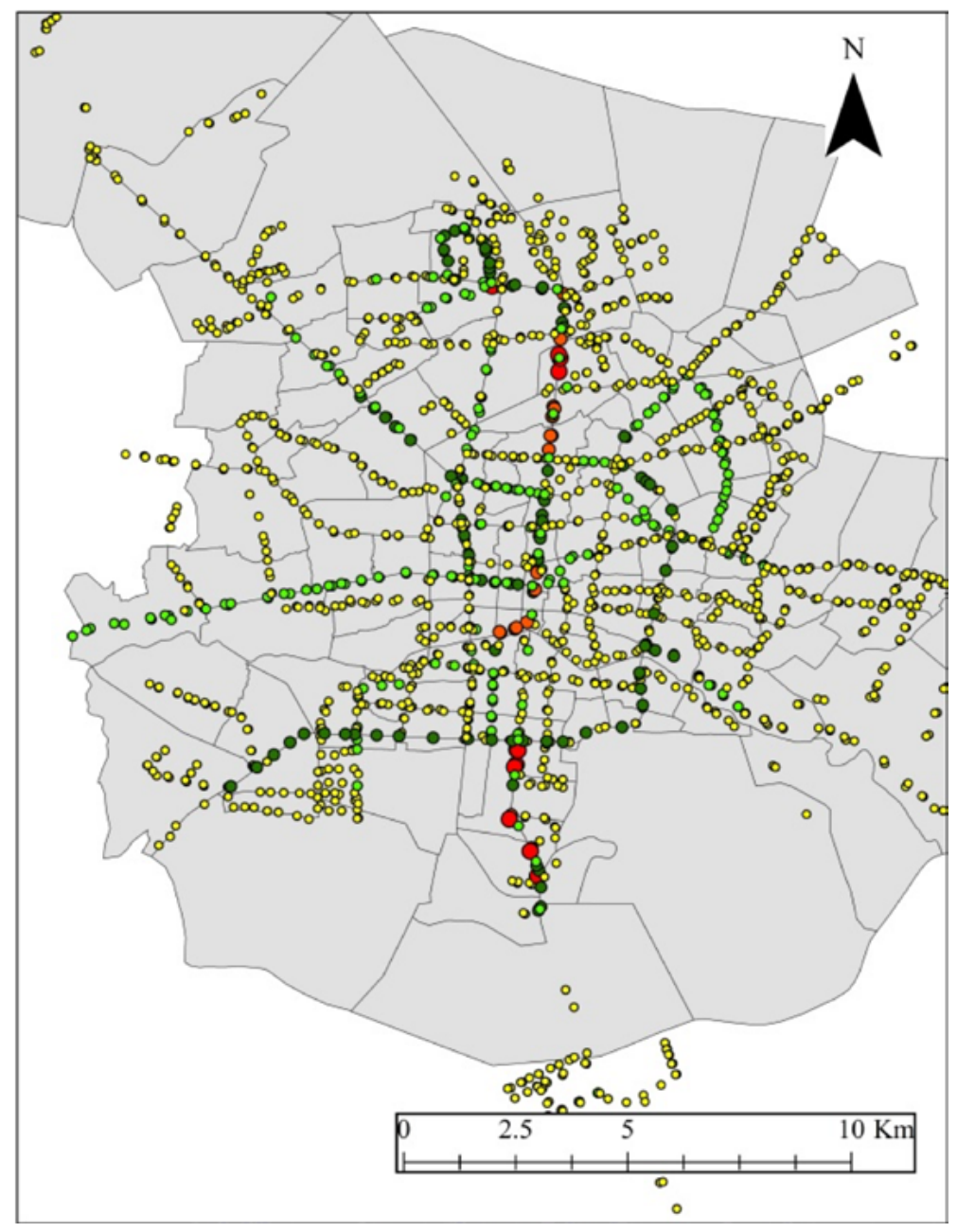

To calculate the amount of need in each traffic zone, the number of residents without a private vehicle was taken into consideration. This group was expected to be totally dependent on public transportation service. The cause of information aggregation in the scale of traffic zones was the availability of data. This information was collected through surveys conducted in comprehensive studies of Isfahan public transportation. To predict the population in the future, the average national population growth rate of Iran was used.

Figure 6 depicts the distribution of need throughout the city. Zones are divided into 10 deciles; the first decile (darkest color) includes zones with the highest need and the tenth decile (lightest color) includes zones with the lowest need.

To calculate the amount of supply of public transportation service in each traffic zone, the power of stations within each traffic zone was summed. The results of the base year, current situation, and future year are depicted in Figures 7, 8, and 9, respectively. To facilitate the display, traffic zones are divided into 10 deciles based on power, where the first decile has the best and the tenth decile has the worst condition in terms of power. 
FIGURE 6.

Distribution of need

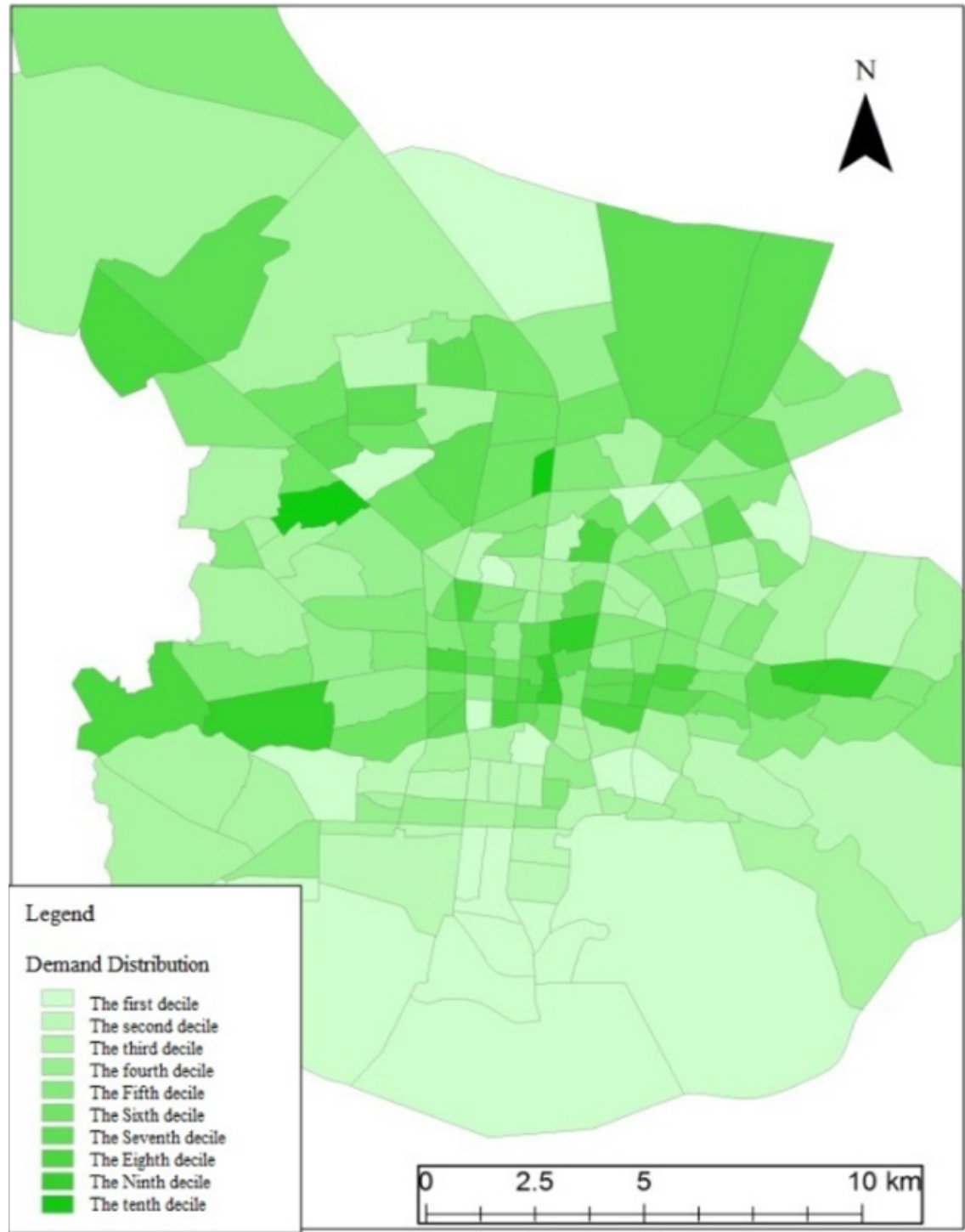


FIGURE 7.

Distribution of power in base situation

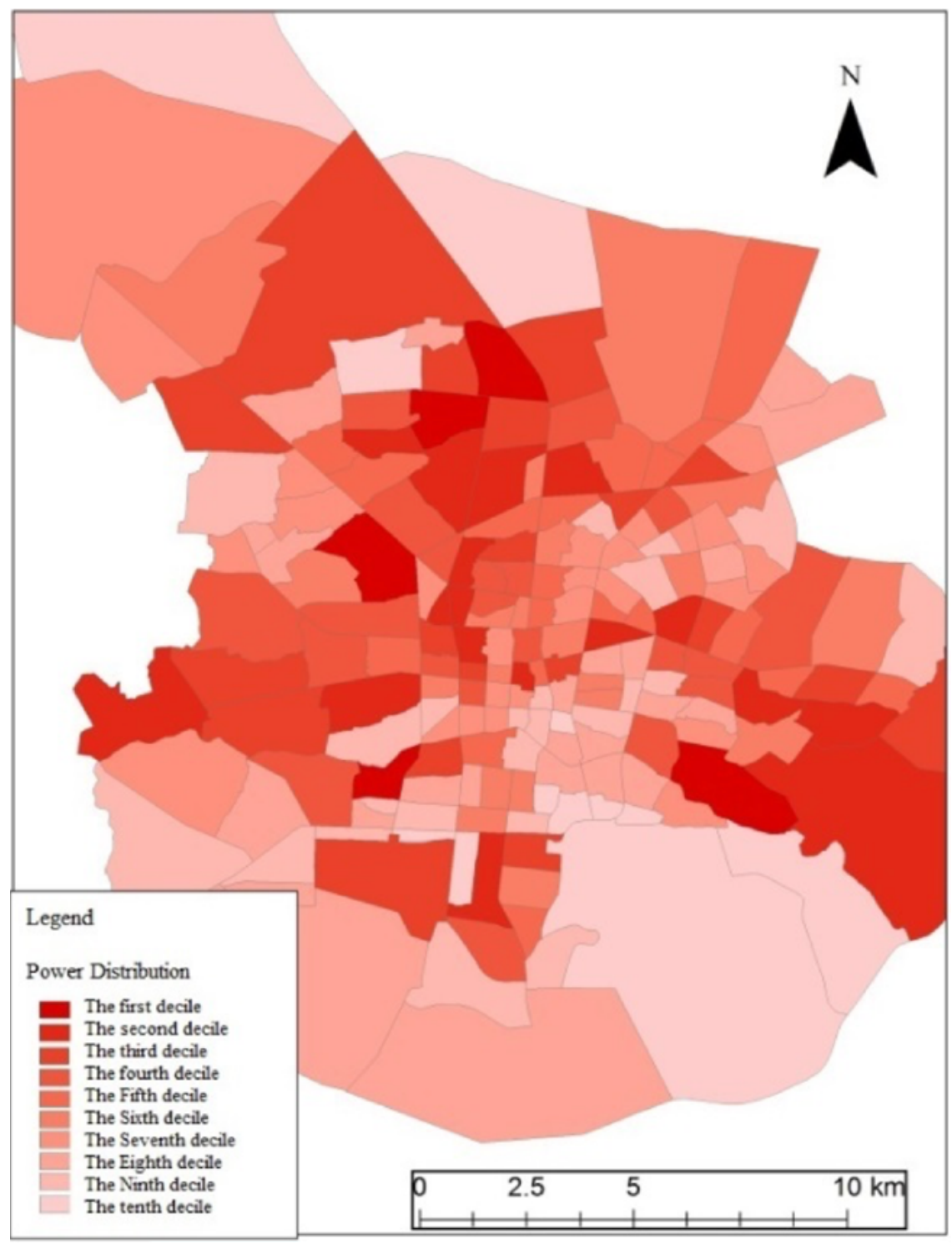


FIGURE 8.

Distribution of power in current situation

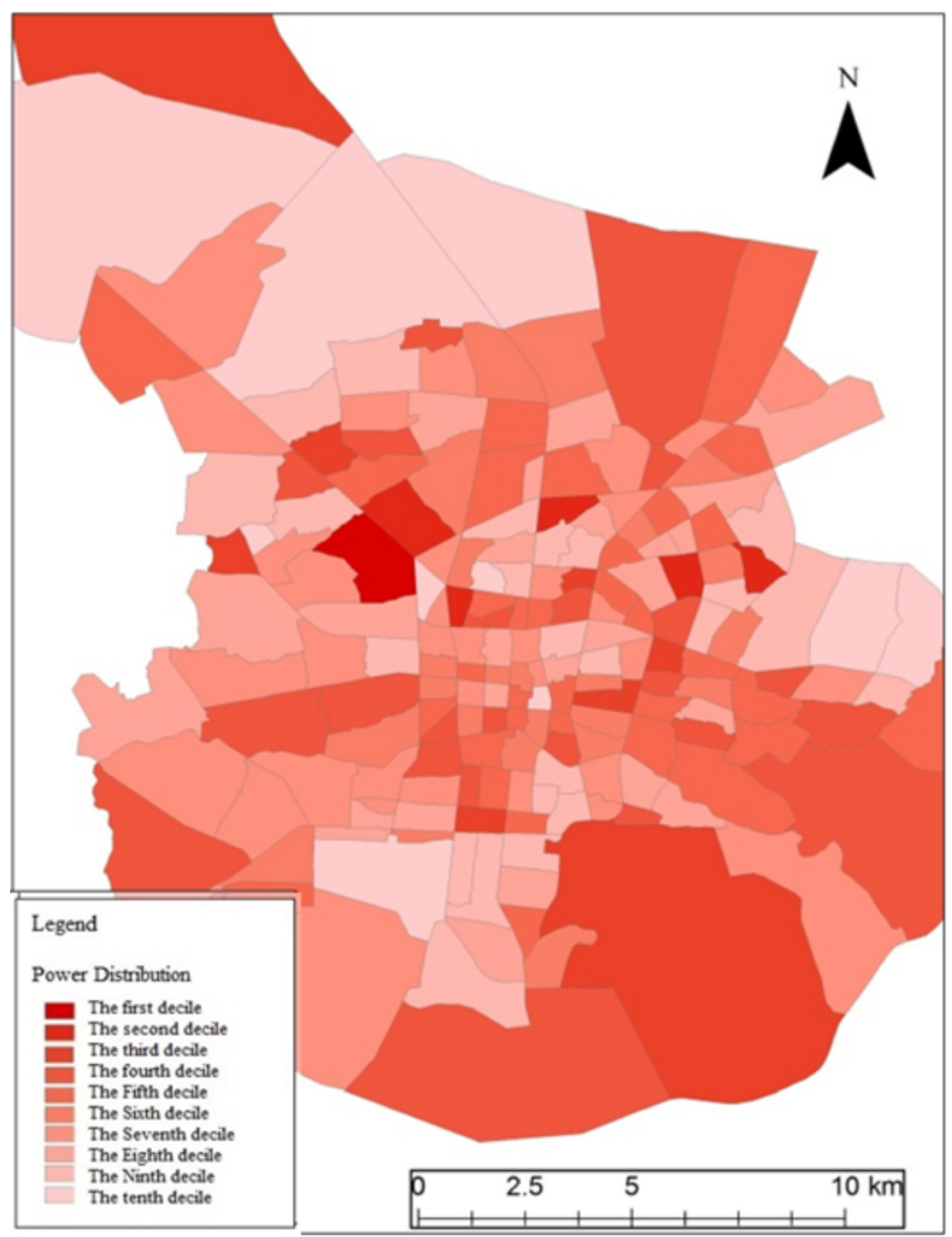


FIGURE 9.

Distribution of power in future situation

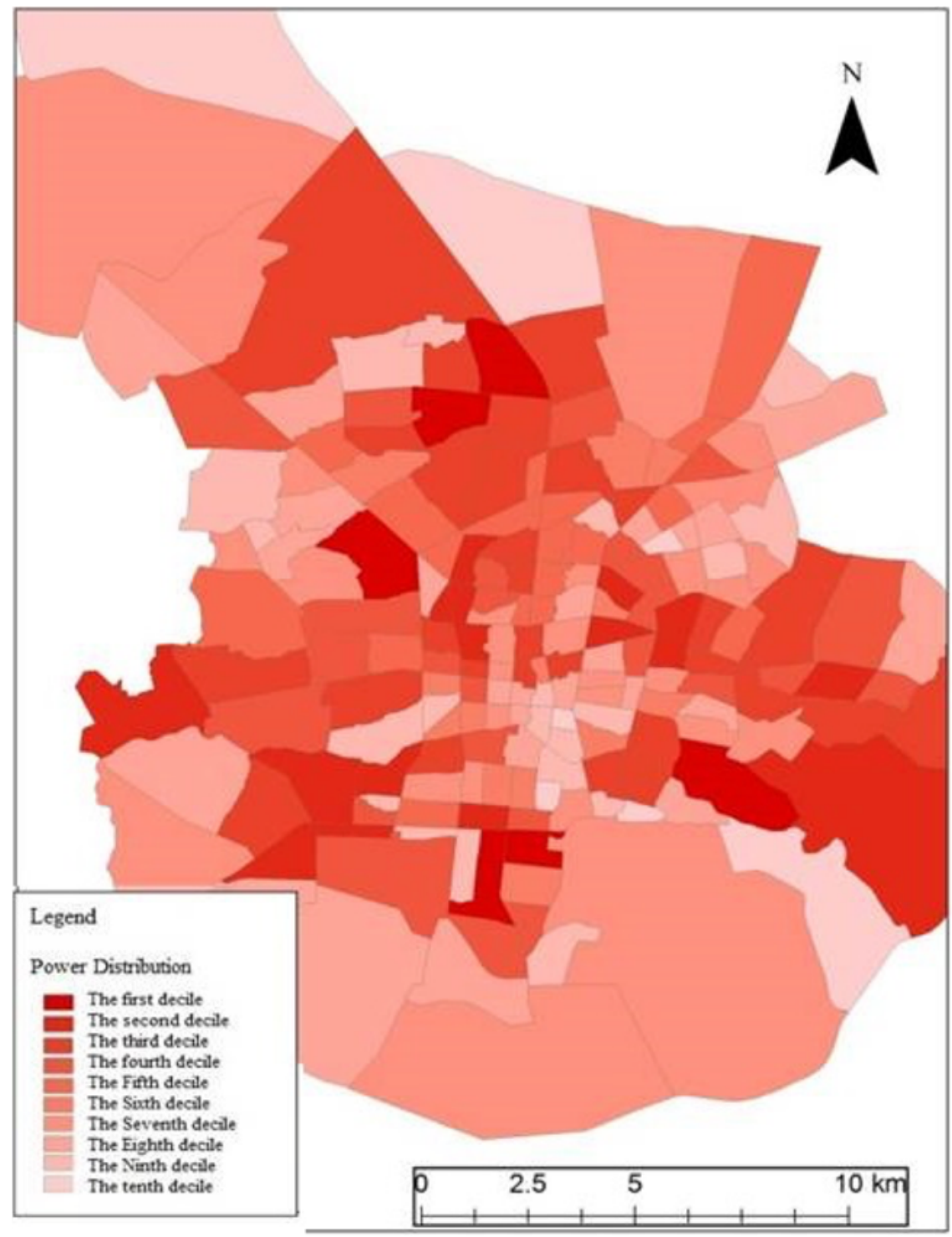

After calculating the values in all TAZs under all three time steps, the values of "need" were pooled into one group and the values of "supply" were pooled separately. Then, each group was sorted and divided into 10 deciles. Therefore, the scale of all the maps pertaining to "need" is the same and the scale of all the maps pertaining to "supply" is the same.

Intensity of deficit in each zone $\left(B_{i}\right)$ was calculated by dividing the normalized value of need $(\mathrm{N})$ to the normalized value of power $(\mathrm{P})$. Normalization was done by dividing the values by their maximum, i.e., $P_{\max }$ and $N_{\max }$.

$$
B_{i}=\left(\frac{N_{i}}{N_{\max }}\right) /\left(\frac{P_{i}}{P_{\max }}\right)
$$


The values of $B_{i}$ for each traffic zone are separated per decile and depicted in Figures 10, 11 , and 12 . Zones with higher disparity among need and power are colored and the first decile zones (lightest) have the most suitable public transportation services compared to the need of residents.

\section{FIGURE 10.}

Distribution of need intensity in base situation

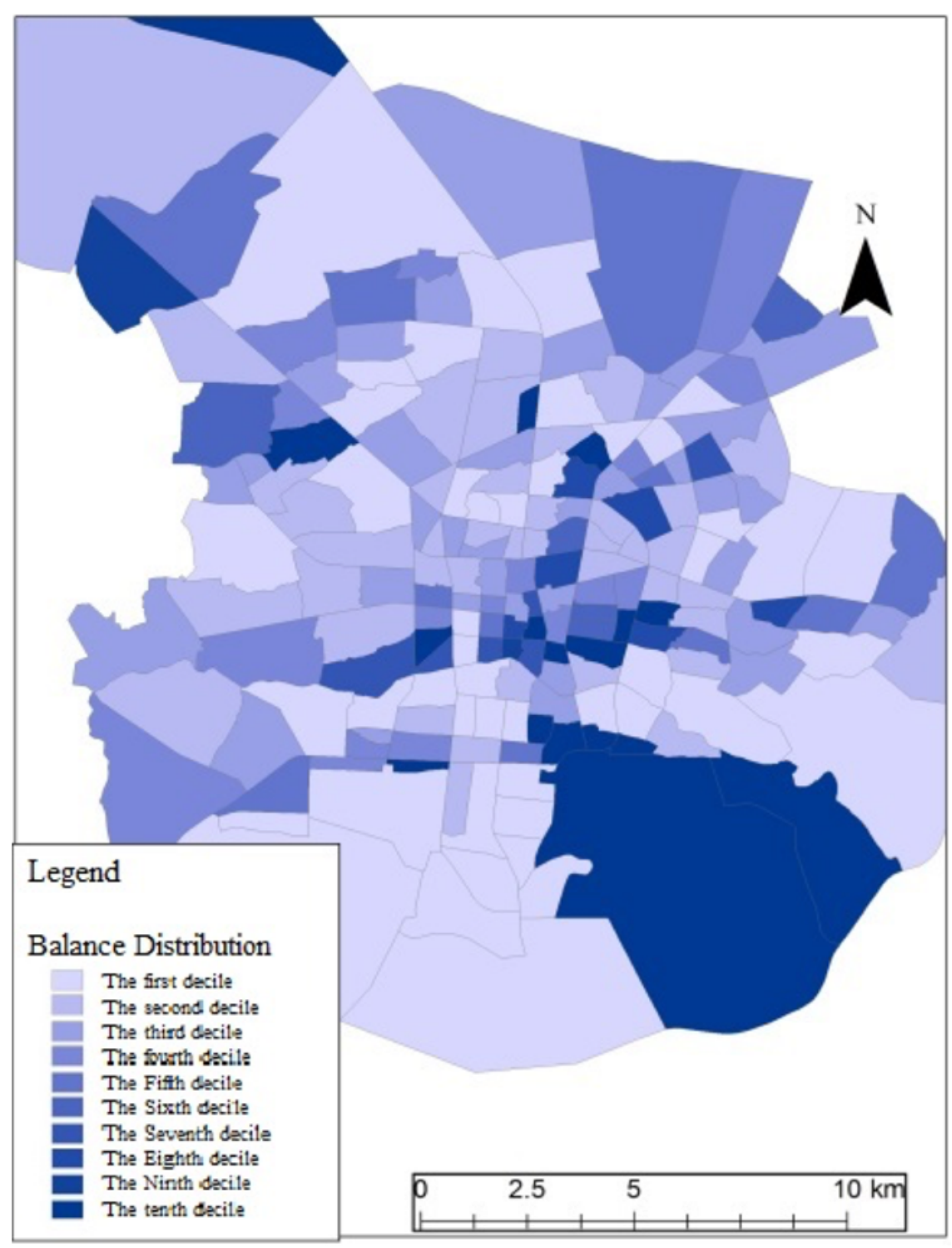


FIGURE 11.

Distribution of need intensity in current situation

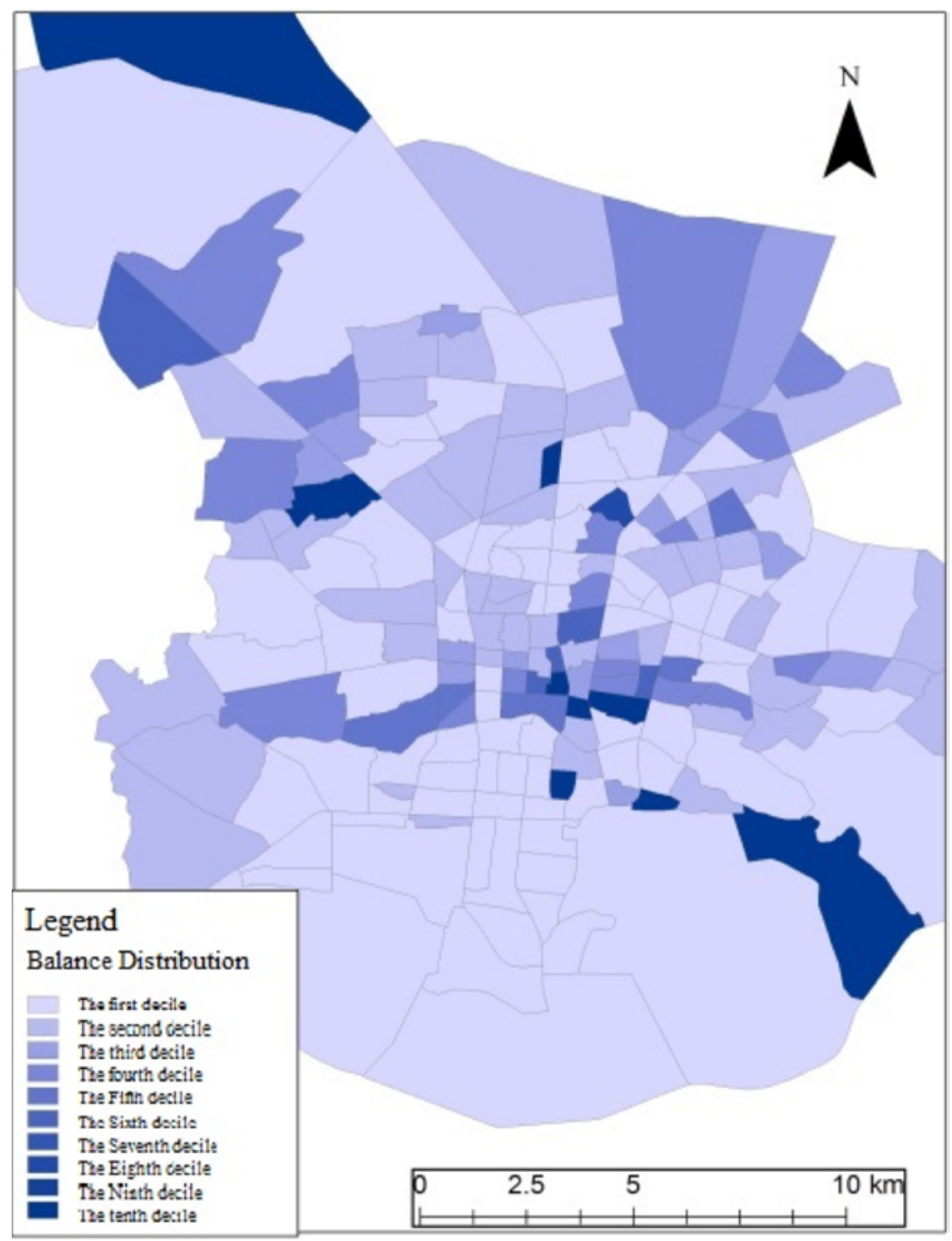


FIGURE 12.

Distribution of need intensity in future situation

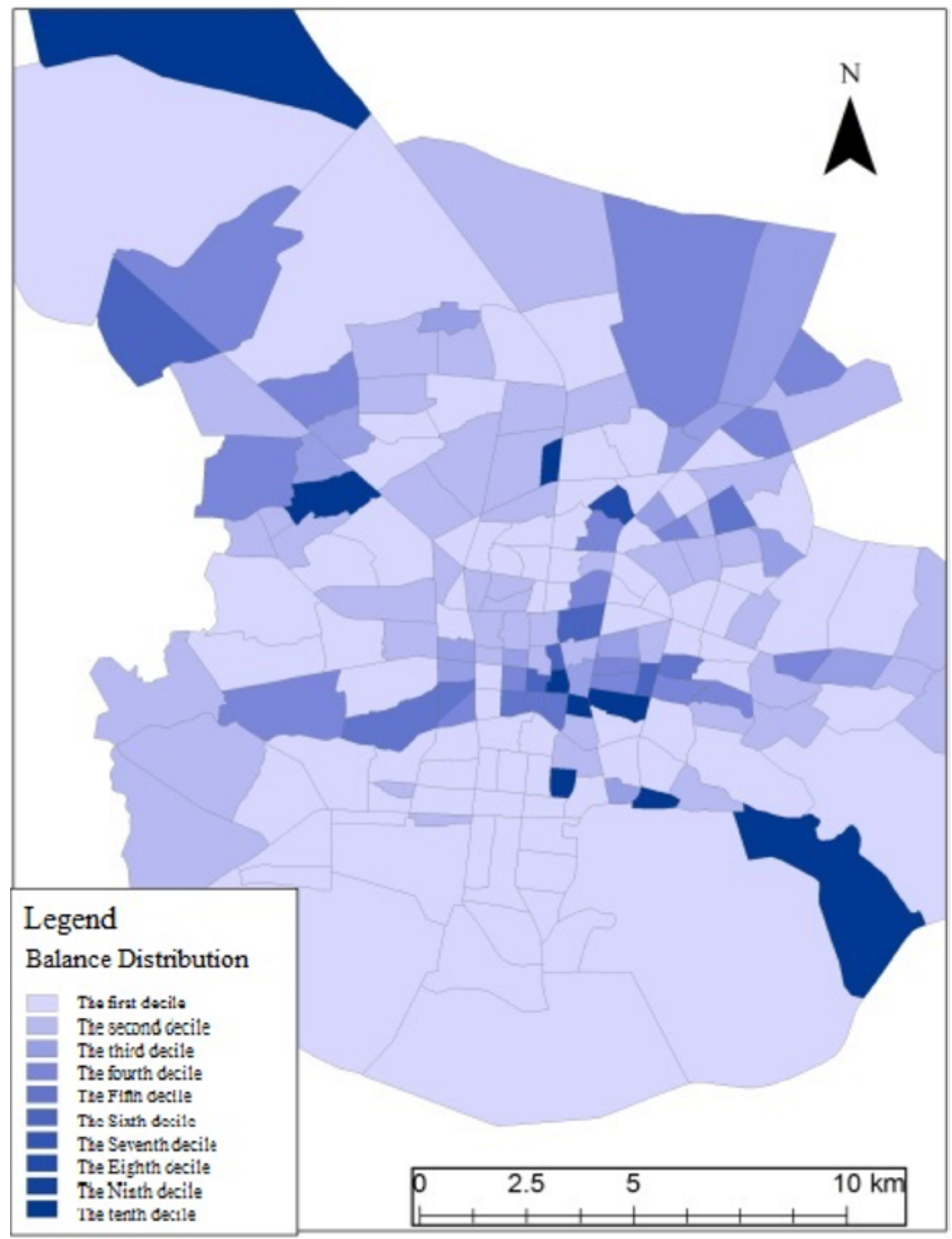

\section{Social Equity Assessment}

To assess equity, the Spearman's rank correlation and the Gini index were calculated. The Spearman's rank correlation value indicates the ranking imbalance between zone power and need. Also, the magnitude of the Gini index indicates the distance of the situation from full equity (perfect equity) condition. Table 1 shows the value of these coefficients in base, current, and future situations.

TABLE 1.

Values of Indices for Three Time Horizons

\begin{tabular}{|l|c|c|c|} 
& Spearman's Rank Correlation & Corresponding $\boldsymbol{t}$ Statistic & Gini Index \\
\hline Base condition & 0.18 & 2.4 & 0.31 \\
\hline Current condition & 0.18 & 2.4 & 0.33 \\
\hline Future condition & 0.04 & 0.5 & 0.33 \\
\hline
\end{tabular}


In the base situation, the Spearman's rank correlation for Isfahan is 0.18 and its corresponding $t$ statistic is 2.4. The acceptable limit for this statistic with 184 degrees of freedom (number of zones minus two) is approximately 1.7. Therefore, the difference between Isfahan zone need rank and received power rank was statistically significant. Consequently, distribution was not proportional. The Gini index in the base situation for Isfahan was 0.31 . Figure 13 illustrates the Lorenz curve and the bisector line (full equity) for this situation.

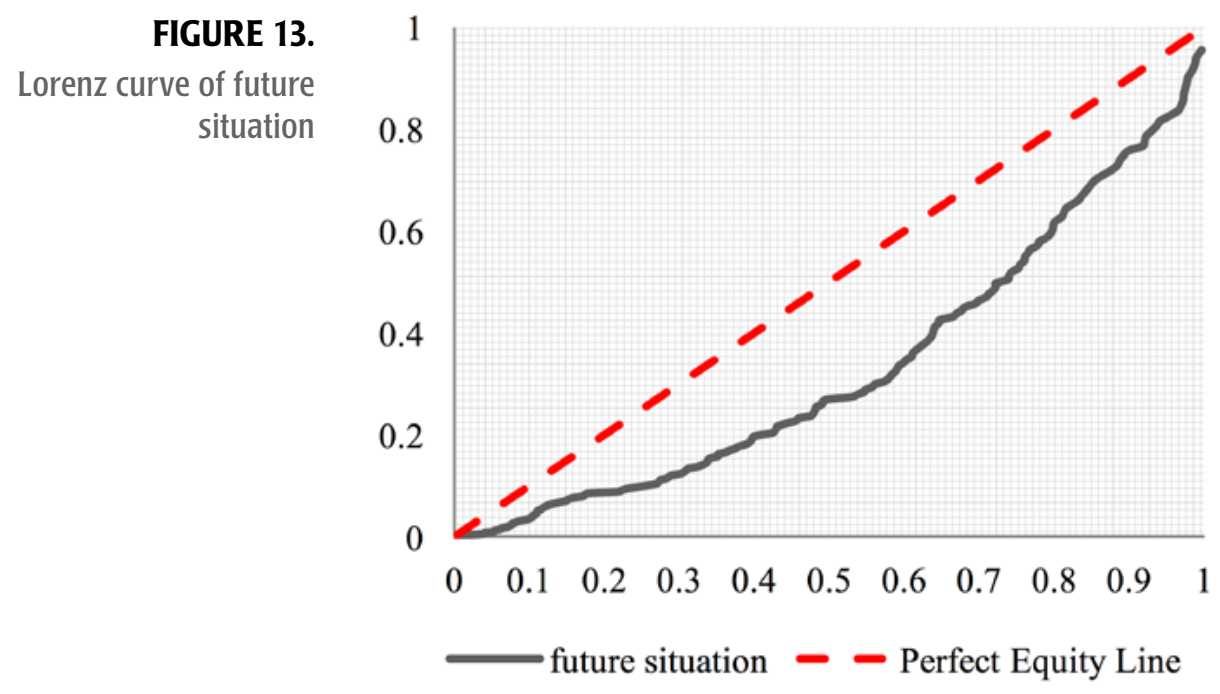

In the current situation, the Spearman's rank correlation coefficient for Isfahan is 0.18 and its corresponding statistic is 2.4 . The critical value for this statistic with 184 degrees of freedom is about 1.7. Therefore, Isfahan zone ranking in term of need is not statistically proportional with its ranking in term of received power. The Gini index pertaining to the current situation of Isfahan is 0.33 , which does not show much improvement compared to the base year.

In the future situation, the Spearman's rank correlation for Isfahan is 0.036 and its corresponding statistic is 0.49 . The acceptable limit for this statistic with 184 degrees of freedom is about 1.7. Therefore, Isfahan zone ranking in term of need is statistically proportional with its ranking in terms of received power. Consequently, power and need distribution will be in adequate conformity. The Gini index pertaining to Isfahan will be 0.33 , which does not show much difference compared to the base and current years.

\section{Conclusion}

The main idea of this paper was that in an equitable system, the geographic distribution of benefits throughout the city should conform to the geographical distribution of resident needs. This is the essence of vertical equity. This study calculated the connectivity power of Isfahan bus stations by incorporating the service hours, frequency, speed, vehicle capacity, and number of accessible stations. The total power presented in each TAZ was calculated as the amount of benefit that TAZ is receiving 
from the transit system. On the other hand, the number of carless citizens in each TAZ was calculated as an index of need to the public transit services in the TAZ.

In the second stage, three conditions of Isfahan were investigated in terms of equity. Until 2012, Isfahan had a transit network consisting of ordinary bus routes running under right-of-way C. Since then, BRT was introduced to the system, and part of the metro system started working. It is planned to complete three more BRT lines and the north-south metro line by 2018. To assess the conformity of demand and supply (i.e., equity), the Spearman's rank correlation and Gini index were calculated throughout the TAZs. First, TAZs were sorted in two separate lists based on their need and power. Then, the rank of each TAZ in two lists was analyzed to determine if the same order was preserved in the two lists. Second, the Gini index was calculated for the whole city under each condition. Results show that although new developments have not contributed to the Gini index (as it remains equal to 0.33 in all three conditions), conformity of demand and supply will reach an acceptable level by 2018 as a consequence of launching new BRT and metro lines.

The proposed framework could be applied to all urban contexts. It may also be used to prioritize tentative scenarios in public transportation of an urban area. As an example for the case of Isfahan, diagonal or radial lines connecting the northwestern part of Isfahan to its southeastern part may serve the zones with highest ratio of need to power and improve the equity status in the city. Including speed, the number of upstream and downstream stations made the calculations on the supply side more realistic.

\section{References}

Bertolaccini K., and N. Lownes. 2014. "Effects of Scale and Boundary Selection in Assessing Equity of Transit Supply Distribution." Transportation Research Record, 2350.

Currie G. 2010. "Quantifying Spatial Gaps in Public Transport Supply Based on Social Needs." Journal of Transport Geography, 18: 31-41.

El-Geneidy, A. M., K. Manaugh, and N. Foth. 2013. "Towards Equitable Transit: Examining Transit Accessibility and Social Need." Journal of Transport Geography, 29:1-10.

Griffin, G. P., and I. N. Sener. 2015. "Equity Analysis of Transit Service in Large AutoOriented Cities in the United States." Transportation Research Board 94th Annual Meeting, 15-0270.

Hensher D., and Z. Li. 2011. "Ridership Drivers of Bus Rapid Transit Systems." Institute of Transport and Logistics Studies.

Iseki, H. 2016. "Equity in Regional Public Transit Finance: Tradeoffs between Social and Geographic Equity." Journal of Urban Planning and Development, 04016010.

Kahn M. E., E. L. Glaeser, and J. Rappaport. 2008. "Why Do The Poor Live in Cities? The Role of Public Transportation." Journal of Urban Economics, 63: 1-24. 
Kaplan, S., D. Popoks, C. G. Prato, and A. A. Ceder. 2014. “Using Connectivity for Measuring Equity in Transit Provision." Journal of Transport Geography, 37: 82-92.

Lemans A. C. D. 2015. "Assessing the Accessibility and Equity of the Urban Public Transport Services." Master's thesis, Delft University. http://repository.tudelft. nl/assets/uuid:d69faad6-4db5-4241-8633-2515a8be04bd/Master_Thesis_Niek_ Lemans_FINAL_pdf.pdf.

Litman T. 2002. "Evaluating Transportation Equity." World Transport Policy \& Practice, $8(2): 50-65$.

Manaugh, K., and A. El-Geneidy. 2012. "Who Benefits from New Transportation Infrastructure? Using Accessibility Measures to Evaluate Social Equity in Transit Provision." Accessibility and Transport Planning: Challenges for Europe and North America: 1035-1053.

Martens K., A. Golub, and G. Robinson. 2012. "A Justice-Theoretic Approach to the Distribution of Transportation Benefits: Implications for Transportation Planning Practice in the United States." Transportation Research Part A, 46: 684-695.

Mishraa S., T. F. Welch, and M. K. Jha. 2012. "Performance Indicators for Public Transit Connectivity in Multi-Modal Transportation Networks." Transportation Research Part A, 46: 1066-1085.

Murray A., and R. Davis. 2001." Equity in Regional Service Provision." Journal of Regional Science, 41: 557-60.

Ong, P. M., and D. Miller. 2005. "Spatial and Transportation Mismatch in Los Angeles." Journal of Planning Education and Research, 25(1): 43-56.

Ricciardi, A. M., J. C. Xia, and G. Currie. 2015. "Exploring Public Transport Equity between Separate Disadvantaged Cohorts: A Case Study in Perth, Australia." Journal of Transport Geography, 43: 111-122.

Siegel, S. 1956. Nonparametric Statistics for the Behavioral Sciences. McGraw-Hill, New York.

Welch T. F. 2013. "Equity in Transport: The Distribution of Transit Access and Connectivity Among Affordable Housing Units." Transport Policy, 30: 283-293.

\section{About the Authors}

Seyed Amir Hosein Mortazavi (amirh_mortazavi@yahoo.com) is an MSc. candidate in the Department of Transportation Engineering at Isfahan University of Technology.

Meisam AKBARZADeh (makbarzadeh@cc.iut.ac.ir) is an Assistant Professor in the Department of Transportation Engineering at Isfahan University of Technology. His research areas of interest include public transportation and complex transportation networks. 